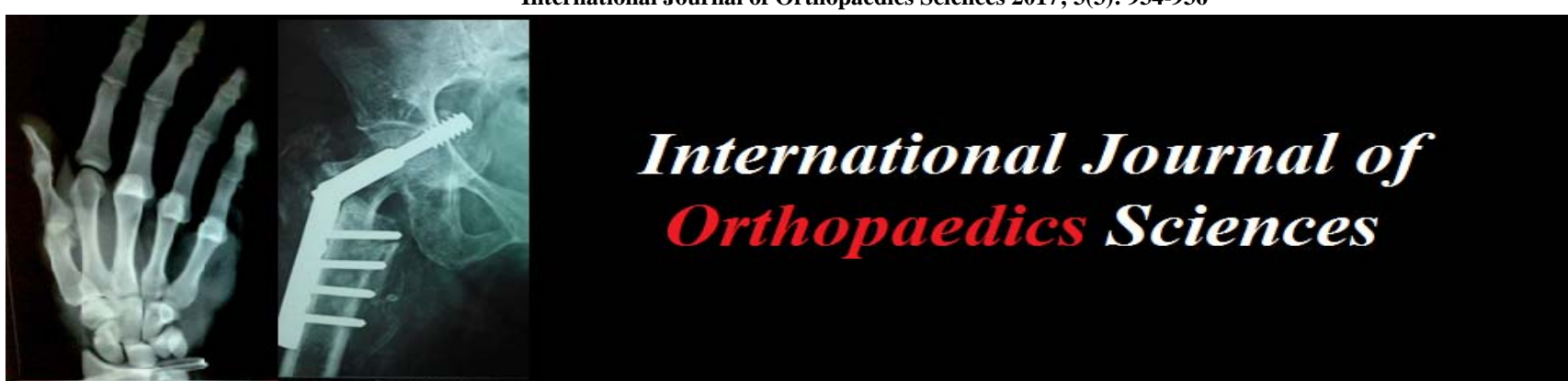

ISSN: $2395-1958$

IJOS 2017; 3(3): 934-936

(C) 2017 IJOS

www.orthopaper.com

Received: 08-05-2017

Accepted: 09-06-2017

Dr. Pramod Bhor

Assistant Professor,

Department of Orthopedics,

Terna Medical College, Navi

Mumbai, Maharashtra, India

Dr. Shikhar D Singh

Assistant Professor,

Department of Orthopedics,

DY Patil Medical College, Navi

Mumbai, Maharashtra, India

Dr. Sachin Y Kale

Professor, Department of Orthopedics, DY Patil Medical

College, Navi Mumbai,

Maharashtra, India

Dr. Divyesh Bukalsaria

Resident, Department of

Orthopedics, DY Patil Medical

College, Navi Mumbai,

Maharashtra, India

Dr. Shubham Padmawar

Resident, Department of

Orthopedics, DY Patil Medical

College, Navi Mumbai,

Maharashtra, India

Dr. Abhinav Garg

Resident, Department of Orthopedics, DY Patil Medical

College, Navi Mumbai,

Maharashtra, India

Correspondence

Dr. Shikhar D Singh

Assistant Professor,

Department of Orthopedics,

DY Patil Medical College, Navi

Mumbai, Maharashtra, India

\section{Clinico-epidemiological profile of lower lumbar disc herniation patients undergoing microlumbar discectomy}

\author{
Dr. Pramod Bhor, Dr. Shikhar D Singh, Dr. Sachin Y Kale, Dr. Divyesh \\ Bukalsaria, Dr. Shubham Padmawar and Dr. Abhinav Garg
}

DOI: $\underline{\text { https://doi.org/10.22271/ortho.2017.v3.i3m.138 }}$

\section{Abstract}

Introduction: The clinical presentations of lumbosacral radiculopathy vary according the level of nerve root or roots involved. Lumbar Discectomy is very commonly performed for this. We aimed to study the clinico-epidemiological profile of the patients who presented to our hospital with low back pain, were diagnosed with lumbar disc herniation and were operated with micro-lumbar discectomy.

Methodology: The study was designed and performed in the Department of Orthopedics, Lokmanya Hospital Chinchwad and Lokmanya Hospital Nigdi, Pune from August 2002 till May 2004. After approval of the institutional ethics committee, we included patients who were admitted and operated for lumbar disc herniation with microlumbar disc surgery. We collected personal, demographical, clinical history and clinical examination findings of the patients. The data was compiled and analysed descriptively using Epi Info software. The frequency tables were prepared and percentages were calculated.

Results: We included 24 patients, 15 patients were males, average age was 45.85 years. L4-L5 was the most commonly involved level of disc involved in our patient population. Radiation of pain towards the right was more commonly seen then left. Majority of the patients had duration of symptoms between 2 to 6 months (42\%). 7 patients had sensory distribution of neurological symptoms, 4 had motor and reflex distribution of symptoms each.

Conclusions: Understanding the clinical and epidemiological profile of patients with disc herniation can help us in identifying candidates for microdiscectomy and better outcomes as a result.

Keywords: Back pain, disc herniation, microdiscectomy, epidemiological

\section{Introduction}

Low back pain with or without pain in the lower extremities has been reported to affect up to $80 \%$ of the people at some time during their lifetimes, to an extent that they are unable to work at their original occupation ${ }^{[1]}$. However, approximately $60 \%$ of the patients are back to work within one week, and only $10 \%$ suffer disabling back pain after six weeks ${ }^{[2]}$. Although data are limited, the estimated lifetime prevalence is approximately 3 to $5 \%$ for adults, with equal rates among men and women ${ }^{[3]}$. The clinical presentations of lumbosacral radiculopathy vary according the level of nerve root or roots involved. The most frequent are the L5 and S1 radiculopathies. Lumbar Discectomy is the most frequently performed neurosurgical procedure in the United States ${ }^{[4]}$. The goals of surgery are to decompress the nerve root and to retrieve free or herniated disc fragments while avoiding instability. Surgical results were optimized by proper patient selection, adherence to proper anatomic landmarks, and adequate illumination and magnification. However, the decision to have surgery requires assessing whether a clinically meaningful reduction in pain and/or disability is more likely to occur spontaneously or with surgery. Since this technique is becoming popular in India as well, we decided to study the clinico-epidemiological profile of the patients who presented to our hospital with low back pain, were diagnosed with lumbar disc herniation and were operated with micro-lumbar discectomy. 
Methodology

\section{Study Design and setting}

The study was designed and performed in the Department of Orthopedics, Lokmanya Hospital Chinchwad and Lokmanya Hospital Nigdi, Pune from August 2002 till May 2004. After approval of the institutional ethics committee, we included patients who were admitted for and operated for lumbar disc herniation with microlumbar disc surgery. During the study period 24 cases were operated and were thus included in the study. Patients presented to our department in the outpatient clinic. All patients first underwent conservative therapy that included rest, pharmacotherapy, and physical therapy in the form of interferential therapy or short wave diathermy, for the minimum period of three weeks.

\section{Sample population}

All the patients were from the near by area around the hospital. Criteria for inclusion were unremitting sciatica, with or without back pain, and/or a neurological deficit that correlated with appropriate level and side of neural compression revealed on CT or MR imaging. Patients who presented with other spinal degenerative conditions such as stenosis or arthritis with herniated disc were not excluded because their symptoms were suggestive of the herniated disc, while the patients with associated bony canal stenosis and spondylolisthesis were excluded. Age, sex, and other medical condition were not the criteria for exclusion of the patients in this study. Preoperatively, routine investigations like haemogram, blood sugar, blood urea and serum creatinine, ECG, chest X-ray and urine examination was done, marker Xray of the lumbo-sacral spine was taken. Patients were advised to stop smoking at last 10 days prior to surgery and stop non-steroidal anti-inflammatory drugs one week prior to surgery. As with all surgical procedures, informed consent was obtained and an explanation of risks, alternatives, and benefits was given. The patients were educated about the likehood of the procedure being performed on an outpatient basis only.

\section{Data Collection and Data Analysis}

We collected personal, demographical and clinical history of the patients. All patients underwent X-ray lumbo-sacral spine anterior - posterior and lateral view on their first visit to the hospital. When improvement in sings and symptoms were not satisfactory with conservative method in three weeks of time the Computed Tomography (CT)-myelography or Magnetic Resonance Imaging (MRI) of lumbo-sacral spine was done. MRI was preferred investigatin of choice. The data was compiled and analysed descriptively using Epi Info software. The frequency tables were prepared and percentages were calculated.

\section{Results}

In our study, we included 24 patients. 15 patients were males and most common age group was 40 to 60 years (54\%). Average age was 45.85 years, ranging between 24 to 64 years. Most of the patients were moderate workers and domestic workers. There were no heavy workers in our patient population (Table 1). $68 \%$ of the patients had a medium built, rest of the patients had a strong built $(21 \%)$ and asthenic (21\%). L4-L5 was the most commonly involved level of disc involved in our patient population. Radiation of pain towards the right was more commonly seen then left (Table 2). Majority of the patients had duration of symptoms between 2 to 6 months $(42 \%) .7$ patients had sensory distribution of neurological symptoms, 4 had motor and reflex distribution of symptoms each. 54\% of the patients underwent CT myelography for diagnosis and rest received MRI before a diagnosis could be made.

Table 1: Socio-demographic characteristics of patients

\begin{tabular}{|c|c|}
\hline Variable & $\boldsymbol{n}$ \\
\hline Number of patients in the study & 24 \\
\hline Age distribution & \\
\hline Less than 40 years & $8(33 \%)$ \\
\hline 40-60 years & $13(54 \%)$ \\
\hline More than 60 years & $3(13 \%)$ \\
\hline Gender distribution & \\
\hline Males & $15(62 \%)$ \\
\hline Females & $9(37 \%)$ \\
\hline Occupation & \\
\hline Housewife & $8(33 \%)$ \\
\hline Light worker & $7(29 \%)$ \\
\hline Moderate worker & $9(38 \%)$ \\
\hline Heavy worker & $0(0 \%)$ \\
\hline Built of the patient & \\
\hline Strong & $5(21 \%)$ \\
\hline Medium & $14(68 \%)$ \\
\hline Asthenic & $5(21 \%)$ \\
\hline
\end{tabular}

Table 2: Clinical information of patients enrolled in the study

\begin{tabular}{|c|c|}
\hline Level of disc prolapse & $\boldsymbol{n}$ \\
\hline L3-L4 & $1(4 \%)$ \\
\hline L4-L5 & $15(63 \%)$ \\
\hline L5-S1 & $8(33 \%)$ \\
\hline Rite of radiating pain & \\
\hline Right & $13(54 \%)$ \\
\hline Left & $11(46 \%)$ \\
\hline Duration of symptoms & \\
\hline Less than 1 month & $7(29 \%)$ \\
\hline Between 2-6 months & $10(42 \%)$ \\
\hline More than 6 months & $7(29 \%)$ \\
\hline Distribution of neurological symptoms & \\
\hline Sensory & $7(29 \%)$ \\
\hline Motor & $4(17 \%)$ \\
\hline Reflex & $4(17 \%)$ \\
\hline Neuroimaging & $13(54 \%)$ \\
\hline Computed Tomography Myelography & $11(46 \%)$ \\
\hline Magnetic Resonance Imaging &
\end{tabular}

\section{Discussion}

It is difficult to estimate the prevalance of back pain, but some surveys have been used to make an estimate. A systematic review publishedin 2012 estimated that the global point prevalence of activity-limiting low back pain lasting for more than one day was $12 \%$ and the one-month prevalence was $23 \%$. ${ }^{[5]}$ A number of risk factors have been associated with back pain complaints include smoking, obesity, age, female gender, physically strenuous work, sedentary work, psychologically strenuous work, low educational attainment, job dissatisfaction, and psychologic factors like anxiety and depression ${ }^{[6]}$.

Almost $90 \%$ of all symptomatic disk herniations occur in the lumbar spine. Most lumbar herniations involve L4-L5 and or L5-S1 levels and thus produce calf pain with compression of the L5 or S1 nerve roots. Other presentations depend on the location of disk herniation, with anterior thigh pain and positive findings of a femoral nerve stretch test being the most common presentation in patients with impingement of L2, L3, or L4 nerve roots. With improvements in advanced imaging techniques, lumbar disc herniations have been increasingly 
recognized in symptomatic and even in asymptomatic individuals [7]. Additionally, imaging exams often show abnormal findings in adults without low back pain, which can make it difficult to correlate symptoms with imaging findings. Disc herniations on MRI are seen in 22 to $67 \%$ of asymptomatic adults and spinal stenosis in $21 \%$ of asymptomatic adults over age $60^{[8]}$. For imaging of the lumbar spine, MRI, CT, and CT myelography are equally sensitive for the diagnosis of disc herniation ${ }^{[9]}$. For routine initial assessment, an MRI is more informative than CT because it can also identify other intraspinal pathologies, including inflammatory, malignant, and vascular disorders. In addition, MRI is not associated with ionizing radiation and is less invasive than CT myelography.

In our study, we found majority of the patients to be males, however equal prevelance in both the genders have been noted ${ }^{[10]}$. The type of occupation has been shown to be associated with disc herniation ${ }^{[11]}$. In our sample majority of the patients were house workers or light workers. $38 \%$ of the patients were moderate workers and none were heavy workers.

\section{Conclusion}

Lower back pain is very common and lumbar disc herniation is the usual cause for this pain. Majority of the patients will present with moderate to severe pain. Understanding their demographic and clinical profiles can help us in diagnosing these patients early, which is associated with better clinical outcomes.

\section{References}

1. Bridge CJ. Innervation of spinal meninges and epidural structures. The Anatomical Record. 1959; 133(3):553-63.

2. Parke WW. Applied anatomy of the spine. In Rothman RH, Simeoné F (eds): The Spine, ed Philadelphia, WB Saunders, 1982; 2(1).

3. Tarulli AW, Raynor EM. Lumbosacral radiculopathy. Neurol Clin. 2007; 25:387.

4. Hodges SD, Humphreys SC, Eck JC, Covington LA. The surgical treatment of far lateral L3-L4 and L4-L5 disc herniations: a modified technique and outcomes analysis of 25 patients. Spine. 1999; 24(12):1243-6.

5. Hoy D, Bain C, Williams G. A systematic review of the global prevalence of low back pain. Arthritis Rheum. 2012; 64:2028.

6. Skovron ML, Szpalski M, Nordin M. Sociocultural factors and back pain. A population-based study in Belgian adults. Spine (Phila Pa 1976) 1994, 19:129.

7. Boden SD, Davis DO, Dina TS. Abnormal magnetic resonance scans of the lumbar spine in asymptomatic subjects: A prospective investigation. J Bone Joint Surg Am. 1990; 72:403-408.

8. Jensen MC, Brant-Zawadzki MN, Obuchowski N. Magnetic resonance imaging of the lumbar spine in people without back pain. N Engl J Med. 1994; 331:69.

9. Bischoff RJ, Rodriguez RP, Gupta K. A comparison of computed tomography-myelography, magnetic resonance imaging, and myelography in the diagnosis of herniated nucleus pulposus and spinal stenosis. J Spinal Disord. 1993; 6:289.

10. Deyo RA, Loeser JD, Bigos SJ. Herniated lumbar intervertebral disk. Ann Intern Med. 1990; 112:598.

11. Seidler A, Bolm-Audorff U, Siol T, Henkel N, Fuchs C, Schug $\mathrm{H}$ et al. Occupational risk factors for symptomatic lumbar disc herniation; A case-control study.
Occupational and environmental medicine. 2003; 60(11):821-30. 